University of Nebraska - Lincoln

DigitalCommons@University of Nebraska - Lincoln

Roman L. Hruska U.S. Meat Animal Research

U.S. Department of Agriculture: Agricultural Center

Research Service, Lincoln, Nebraska

$6-2012$

\title{
Using Resistivity Arrays to Monitor Groundwater Impacts near Runoff Holding Ponds
}

\author{
Roger A. Eigenberg \\ USDA-ARS, USU.S. Meat Animal Research Center, Clay Center, NE, roger.eigenberg@ars.usda.gov \\ Bryan L. Woodbury \\ U.S. Meat Animal Research Center, bryan.woodbury@ars.usda.gov
}

Follow this and additional works at: https://digitalcommons.unl.edu/hruskareports

Part of the Animal Sciences Commons

Eigenberg, Roger A. and Woodbury, Bryan L., "Using Resistivity Arrays to Monitor Groundwater Impacts near Runoff Holding Ponds" (2012). Roman L. Hruska U.S. Meat Animal Research Center. 170. https://digitalcommons.unl.edu/hruskareports/170

This Article is brought to you for free and open access by the U.S. Department of Agriculture: Agricultural Research Service, Lincoln, Nebraska at DigitalCommons@University of Nebraska - Lincoln. It has been accepted for inclusion in Roman L. Hruska U.S. Meat Animal Research Center by an authorized administrator of DigitalCommons@University of Nebraska - Lincoln. 


\title{
Using Resistivity Arrays to Monitor Groundwater Impacts near Runoff Holding Ponds
}

\author{
Roger A. Eigenberg and Bryan L. Woodbury \\ Department of Environmental Management Research Unit, USDA-ARS, USMARC, Clay Center, NE 68933-0166 \\ Email: roger.eigenberg@ars.usda.gov, bryan.woodbury@ars.usda.gov
}

\begin{abstract}
*
Mineral and organic salts from beef manure contained in precipitation runoff from feedyard pen surfaces can alter the conductivity properties of soil and water receiving it. Typically, holding ponds are constructed to control runoff from concentrated animal feeding operations. The integrity of these holding ponds has come under increased scrutiny since leakage has the potential to affect soil and groundwater quality. Traditionally, ponds are monitored by installing monitoring wells at key locations to evaluate the impact of these ponds on the environment. These monitoring wells are expensive and subject to ambiguous interpretation. A subsurface resistivity array was installed at a beef cattle feedyard located at the U.S Meat Animal Research Center, Clay Center, Nebraska (Feedyard A) and at a cattle feeding cooperator site (Feedyard B). Array probes were permanently installed at Feedyard A (16 probes spaced $6.1-\mathrm{m}$ apart at a depth of $30 \mathrm{~cm}$ ) and at Feedyard B $(32$ probes spaced $3.05-\mathrm{m}$ apart at a depth of $50 \mathrm{~cm}$ ). Weekly readings from each site were evaluated to monitor the stability of the zone of hydration near the pond. The low hydraulic conductivity soils at Feedyard A provided a very quiescent environmental system to evaluate the resistivity array's inherent measurement stability. Seasonal changes could easily be accounted for by variation in seasonal soil temperatures. The Feedyard B site was typified by coarse textured parent material that had high hydraulic conductivity properties. This site experienced dynamic changes week to week and throughout the season. The resistivity array system was able to adequately measure these dynamics. Additional analysis using difference maps improved the illustration of the resulting dynamic. The results of this study indicate that the resistivity array system has the potential to improve monitoring of runoff holding ponds and warrants additional validation.
\end{abstract}

\section{Introduction}

The National Pollution Discharge Elimination System CAFO (confined animal feeding operation, cattle feedyards with 1,000 head capacity or more) rule states that feedyards designated as CAFOs must be designed, constructed, operated, and maintained to contain all manure/wastewater including runoff and direct precipitation from a 25-year, 24-hour storm event. Feedyards typically comply with the liquid runoff requirements through construction of holding ponds of sufficient size to meet designated standards. Feedyard runoff holding ponds contain elevated levels of suspended and dissolved organic compounds, salts and other nutrients (including nitrate-nitrogen, ammonia,

*Mention of trade names or commercial products in this publication is solely for the purpose of providing specific information and does not imply recommendation or endorsement by the U.S. Department of Agriculture. and chloride ions) (Gilley et al., 2009). In addition, this runoff can contain other compounds of environmental interest such as pharmaceutical active and endocrine disrupting compounds (Dolliver and Gupta, 2008). Thus, protecting the underlying soil and ground water from these pollutants is critical.

Some states regulate animal waste lagoons and storage ponds by setting limits on either the maximum infiltration rate or the maximum saturated hydraulic conductivity of the media lining the pond (Parker et al., 1999a). Additional studies have shown that organic solids in the manure forms a seal as it passes through soil liners helping to reduce infiltration rates (Cihan et al., 2006; Chang et al., 1974). Numerous studies have been conducted to measure and predict infiltration flux (Culley and Phillips, 1982; DeTar, 1979; Roswell et al., 1985; Miller et al., 1985; Barrington et al., 1989) with inconsistent conclusions. Tyner and Lee (2004) concluded that relying on the presence of a manure seal to limit flux may not be warranted since it is not present 


\section{Journal of Environmental and Engineering Geophysics}

initially, and may sustain damage if the liquid manure is mixed and/or pumped down. Also, this manure seal does not adequately limit infiltration on the pond side walls which can be a major source of leakage (Parker et al., 1999b). Monitoring potential seepage is necessary to ensure protection of ground water and soil impacted by holding ponds.

Physical, microbial and geochemical conditions interact over time as the evolution of groundwater solution is transported through the aquifer (Barcelona et al., 1983). These subsurface environmental conditions present challenges for successfully monitoring the impact of runoff holding ponds on groundwater quality. Therefore, methods of monitoring seepage from holding ponds are limited. Ham (1999) used floating evaporation pans, precision waste level recorders and meteorological models to estimate change in waste level and evaporation from cattle and swine holding ponds. A change in pond level greater than the estimated evaporation was attributed to seepage; hence, seepage rates could be estimated for the monitored pond. While this approach has the advantage of being non-invasive, it has the disadvantage of being affected by winds greater than $10 \mathrm{~m} \mathrm{~s}^{-1}$ that caused overflow of the evaporation pans, requiring a restart of the water balance. Furthermore, this method does not distinguish either the location of the leak nor the extent of leak in the affected pond.

Monitoring wells are the mainstay for detecting subsurface discharge from feedyard runoff holding ponds. For example, the state of Nebraska currently has 237 operations with a series of wells that require semi-annual monitoring (NDEQ, 2011). The proper location of a monitoring well requires close attention to the specific site's geologic and hydrologic characteristics. Sufficient information of these characteristics for any particular site is rare; therefore, best estimates are made for determining the ideal number and location required for site assessment. A typical minimal installation would have three wells; one well is typically located $100-200 \mathrm{~m}$ up gradient of the holding pond to record water quality conditions prior to flowing down gradient under the lagoon/pond. Two monitoring wells are located adjacent to each holding pond in the down gradient flow direction to more quickly identify possible impacts to the groundwater (NDEQ, 2011). Installation of monitoring wells requires careful attention to selection of the well casing composition, the well screen material and size as well as casing sealing methods and substance. Such installations can be costly and, if improperly constructed, can be a source of contamination via a direction conduit to the ground water along the well casing wall (Barcelona et al., 1985). Alternative methods using geophysical techniques have the potential for altering traditional pond monitoring by providing subsurface information of the site, supplement information on pond discharge performance and reducing the total number of wells required for adequate monitoring.

One geophysical tool with potential to enhance monitoring efforts is the resistivity array. This technique had its origin in the 1920's based on work of the Schlumberger brothers (Loke, 2004). The basic array is constructed of four probes; the two outer probes supply current and the two inner probes are used to read the potential or voltage which, when combined with the excitation current, yields an apparent resistance. The spacing between the probes establishes the approximate depth of the array's measurement. This basic construct has been used by geophysicists, archaeologists, mineral and oil prospectors, and geologists since its inception. More recently, such arrays have new applications including mapping of landfills to determine extent of impact (Carpenter et al., 1990). The successful application of these methods to monitoring of waste management sites relies on conductivity differences between the parent material and the potential contaminant plume. Additionally, monitoring requires a stable and accurate measurement technology.

Agricultural applications of resistivity methods have been limited to field mapping systems (Allred et al., 2008). One commercial system is the Veris 3,100 Soil EC Mapping System (Veris Technologies); the Veris uses six rolling steel coulters that penetrate the soil providing two depths via two Wenner arrays (Allred et al., 2008). The Veris is typically pulled behind a towing vehicle that makes a serpentine path through a field, thus creating a two-dimensional map of the field to the specified depth. A capacitively coupled system called an OhmMapper TR1 (Geometrics, Inc.) produces readings similar to a conventional galvanic contact electrode array; however, the signals are coupled to the soil by a source signal of $12 \mathrm{kHz}$ to $20 \mathrm{kHz}$ and special cable to provide coaxial capacitive coupling. The OhmMapper is pulled through an agricultural field and apparent resistivities are collected by a datalogger. The use of galvanic resistivity methods in agriculture have concentrated on field scale, mobile units. The application of stationary, multielectrode resistivity arrays has had limited application in agriculture since these systems typically require tedious/expensive switching systems and a cumbersome array of probes and wires. Currently available technology may alleviate some of the drawbacks, allowing the capabilities of these methods to be explored and utilized.

The objective of this work was to determine whether resistivity arrays had sufficient stability, resolution and sensitivity to monitor temporal dynamics at boundaries near cattle waste management holding ponds. This preliminary study was intended to develop 
Eigenberg and Woodbury: Monitoring Groundwater Impacts near Runoff Ponds using Resistivity

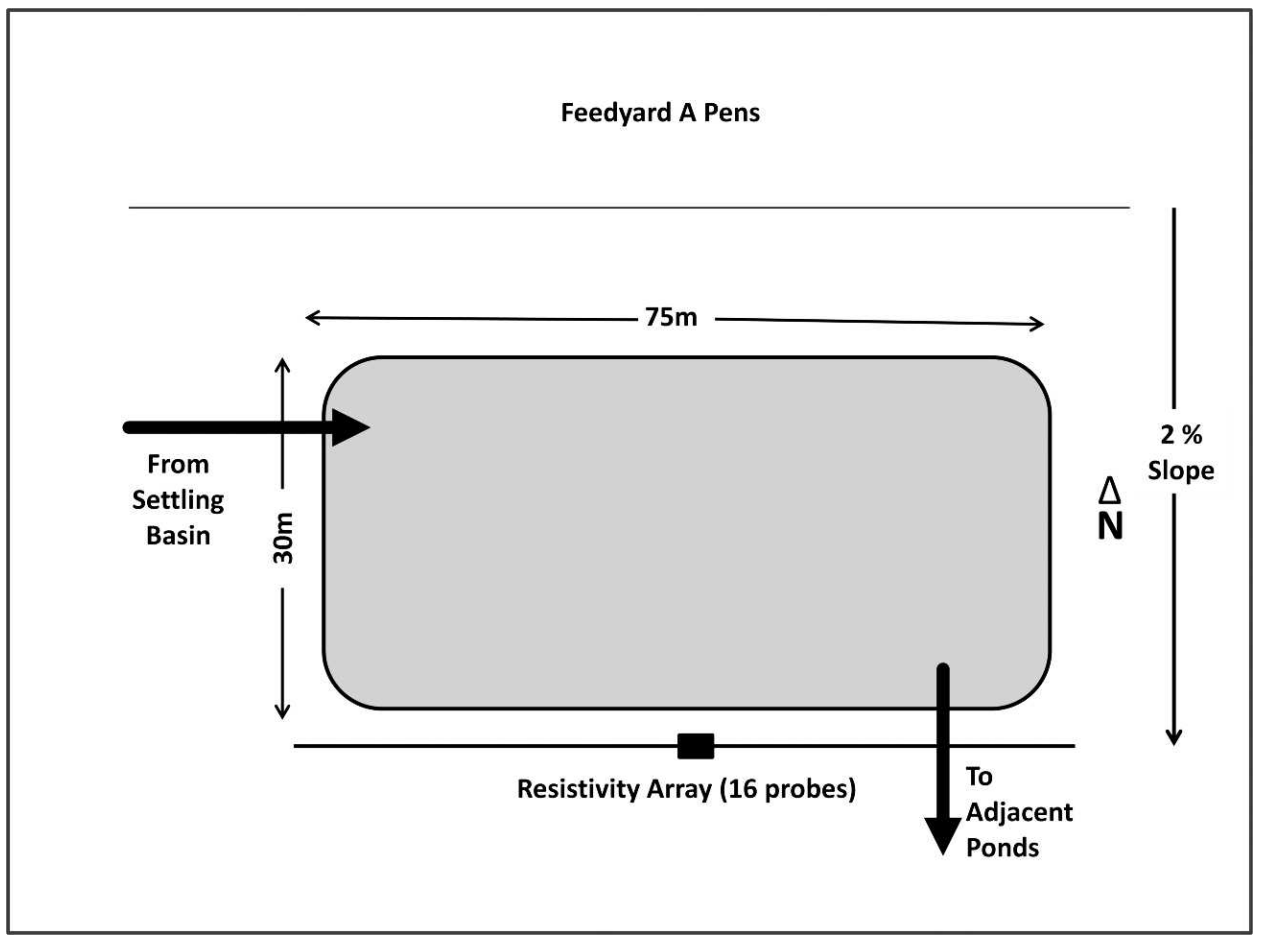

Figure 1. Feedyard A contains four liquid impoundment structures connected in series; the first structure is used as a solids settling basin. The second pond (shown in this schematic) is monitored by the resistivity array. Depth to ground water is approximately $40 \mathrm{~m}$.

methods, investigate available technology, examine stability, consider seasonal influences, and test practicality of the use of resistivity methods. Ground-truth validation of these systems is planned upon establishment of the methods.

\section{Materials and Methods}

\section{$\underline{\text { Sites }}$}

Two sites were selected for testing: the first is located at the U.S. Meat Animal Research Center feedyard near Clay Center, Nebraska (designated as Feedyard A), and the second is a producer cooperator located in central Nebraska designated as Feedyard B. The soil at Feedyard $\mathrm{A}$ is a Crete silt loam (fine, montmorillonitic, Mesic Pachic Argiustolls); Feedyard B is a Brocksburg loam (fine-loam over sandy or sandy-skeletal, mixed, superactive, calcareous, Mesic Pachic Argiustolls). Depth to ground water is over $40 \mathrm{~m}$ at Feedyard A; groundwater level at Feedyard B varies around $4 \mathrm{~m}$. Feedyard A is a 6,500 head feedyard with the holding ponds servicing approximately 3,500 head; Feedyard B is about 10,000 head with two holding ponds servicing the feedyard. The dimensions of the pond at Feedyard A were 75-m length $\times 30$-m wide $\times 5$-m deep, and at Feedyard B were $150-\mathrm{m}$ length $\times 60-\mathrm{m}$ wide $\times 4-\mathrm{m}$ deep. Annual average precipitation for both sites is 66 to $72 \mathrm{~cm}$.
Management of the Sites

Feedyard A contains four liquid impoundment structures (Fig. 1) connected in series; the first structure is used as a solids settling basin. The second pond in the series is the one monitored by the resistivity array. Two additional ponds are in the series of holding ponds. The ponds are pumped as needed to maintain runoff capacity of the ponds; timing is determined by the holding capacity of the soils to which the effluent is applied.

Feedyard B is equipped with two holding ponds (Fig. 2); one pond services the south series of pens with the second pond servicing the north series of pens. The north pond was selected as the monitored site since it was equipped with monitoring wells and had a history of site evaluation. Effluent from these ponds is used for irrigation of cropland and is scheduled according to irrigation requirements and water holding capacity of the soil.

\section{Equipment and Initial Tests}

A commercial digital soil resistance meter (Miller 400D, manufactured by M. C. Miller Co.) was used during this study. The instrument was operated as an in-line, fourelectrode device (Fig. 3) with the two outer probes providing excitation and the two inner probes reading the resultant signal (Wenner-Alpha configuration). The 
Journal of Environmental and Engineering Geophysics

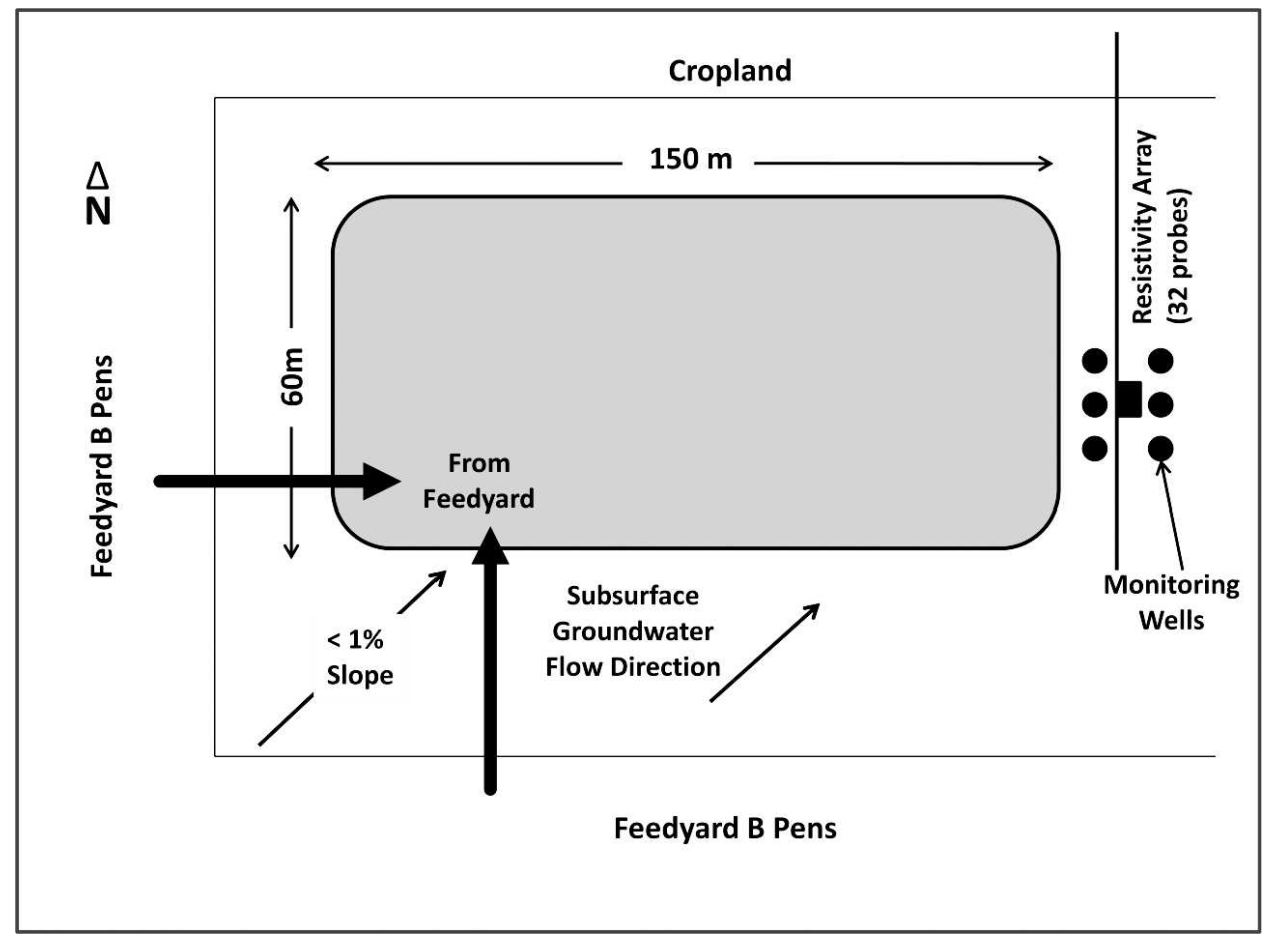

Figure 2. Feedyard B is equipped with two holding ponds; the north pond (shown in this figure) was selected as the monitored site since it was equipped with monitoring wells and had a history of site evaluation. Effluent from this pond is used for irrigation of cropland and is scheduled according to irrigation requirements and water holding capacity of the soil. Groundwater depth averages $4 \mathrm{~m}$.

Wenner-Alpha configuration has the strongest signal strength of the commonly used arrays and is relatively sensitive to vertical changes in resistivity; however, this configuration is less sensitive to horizontal changes (Loke, 2004). The instrument generates an $82.2 \mathrm{~Hz}$ excitation signal with the ammeter and voltmeter using a narrow bandpass filter centered on $82.2 \mathrm{~Hz}$ to reduce the effects of stray interference. Initial tests were conducted using an array of 16 probes through which each of the four-electrodes of the Wenner-Alpha array were switched (Fig. 4).
Basic resistivity theory is well developed (Loke, 2004); the geometry factor $\mathrm{K}$ for a Wenner-Alpha configuration (Fig. 3) with probe spacing, a, is given as:

$$
\mathrm{K}=2 \pi \mathrm{a} \text {, }
$$

where $\mathrm{a}$ is probe spacing. The geometry factor is multiplied by the instrument reading to yield a corrected estimate of resistivity for the given probe spacing:

$$
\rho=\mathrm{K} \mathrm{r},
$$

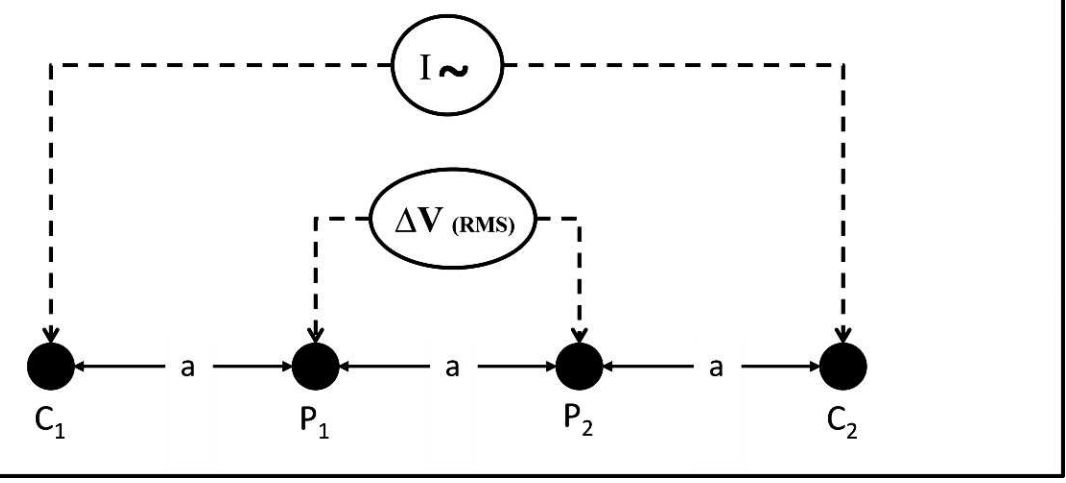

Figure 3. The instrument was operated as an in-line, four-electrode device with the two outer probes providing alternating current excitation and the two inner probes reading the resultant signal (Wenner-Alpha configuration). 


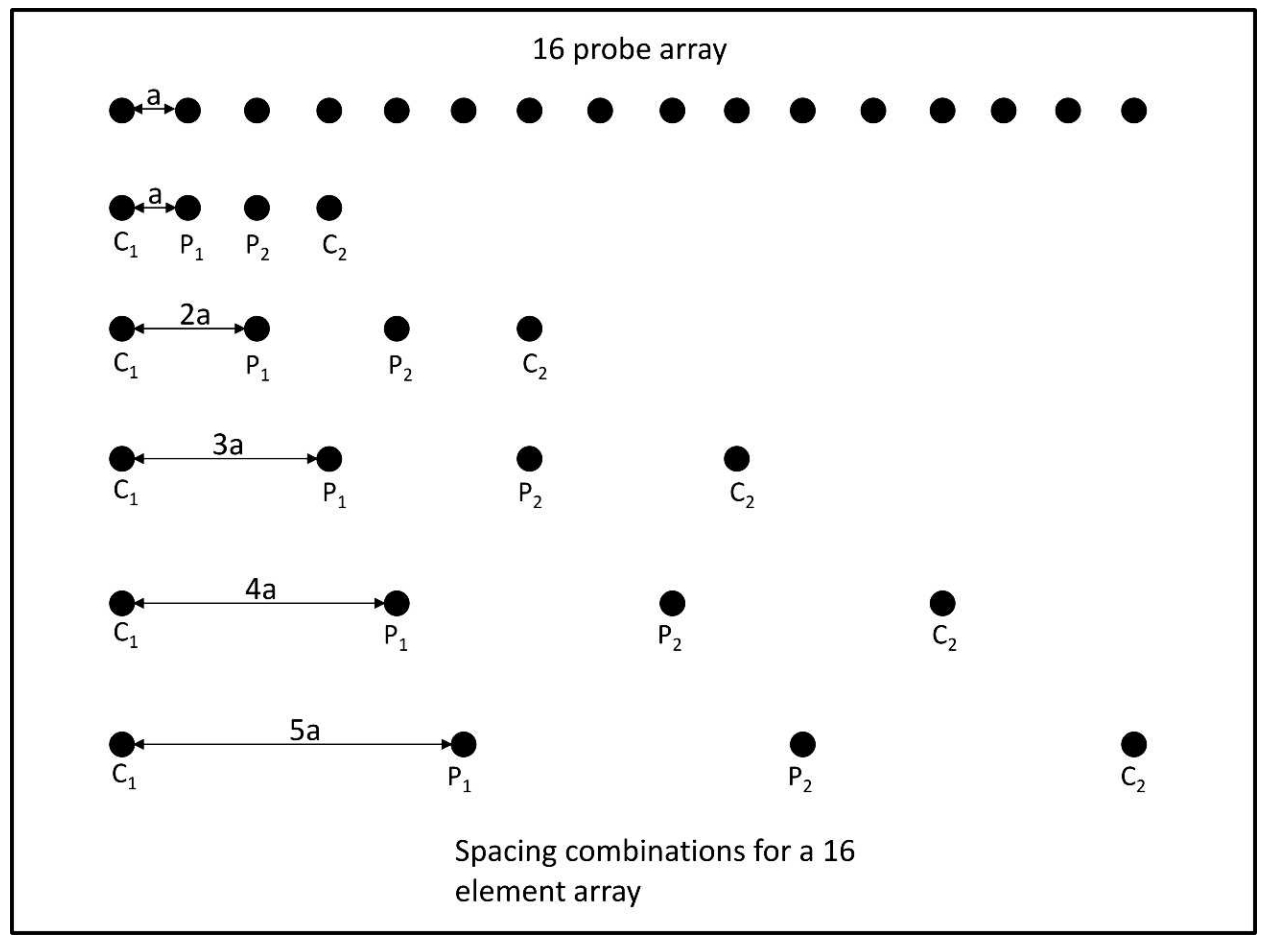

Figure 4. Arrays of 16 probes (shown here) and 32 probes were used in initial tests and for permanent installation at feedyard sites. The figure illustrates the method of increasing spacing between probe connections to create new geometries that provide greater effective depths. The four sequential probes were operated as a Wenner-Alpha array.

where $\rho$ is estimated resistance at an estimated depth $z_{e}$, and $\mathrm{r}$ is the instrument reading (voltage/current).

There are differing views on the effective depth of investigation for a given array spacing and configuration. Some authors choose the maximum point of the sensitivity function (Loke, 2004) as the depth of investigation; however, Loke (2004) states that a more robust estimate of depth is the "median depth of investigation", at this depth the upper section of the earth has the same influence on the measured potential as the lower section. This depth for a Wenner-Alpha configuration is estimated as (Loke, 2004):

$$
\mathrm{z}_{\mathrm{e}}=0.519 \mathrm{a} \text {. }
$$

A 16-element portable resistivity array assembly was built that included a cluster of precut wires bound together; quick-attach connectors were used on the probe ends so steel probes could be attached/detached. Probes were custom-made $(0.635-\mathrm{cm}$ diameter $)$ stainless steel probes (Fig. 5) pointed on one end to facilitate insertion into the soil and threaded on the other end to allow attachment to wires via terminals. The array included a junction box and a connection panel allowing combinations of probes to be selected and resistivity values read using the Miller 400D. A 16-element resistivity array allowed a subsurface slice of apparent resistivity to be examined. The four-electrode configuration is moved laterally across the region of interest by sequentially incrementing the probes in the junction box. Increasing depth is accomplished by incrementing the spacing between the probes. This somewhat tedious method allows 35 distinct points to be recorded (Fig. 4) with a 16probe array.

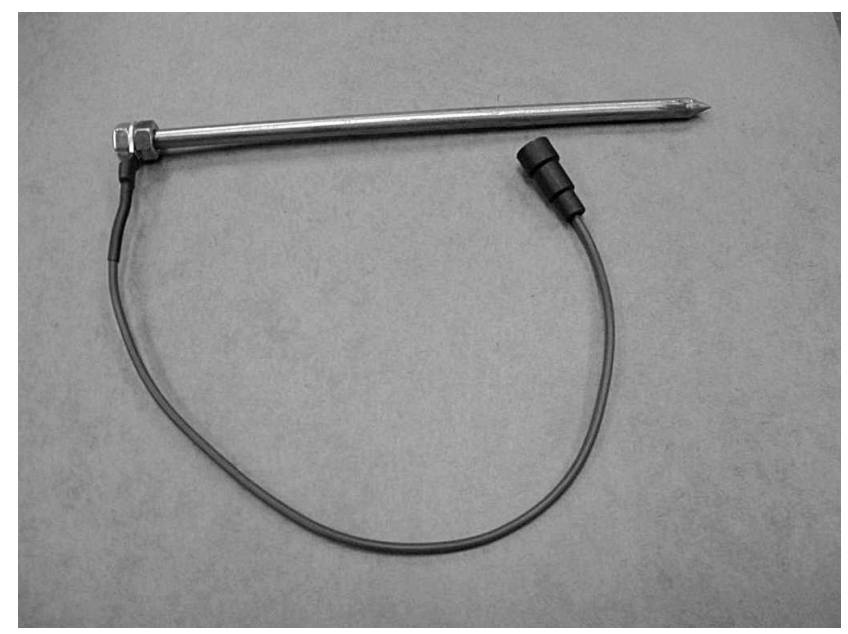

Figure 5. Probes were custom-made $(0.635-\mathrm{cm}$ diameter) stainless steel probes pointed on one end to facilitate insertion into the soil and threaded on the other end to allow attachment to wires via terminals. 
Journal of Environmental and Engineering Geophysics

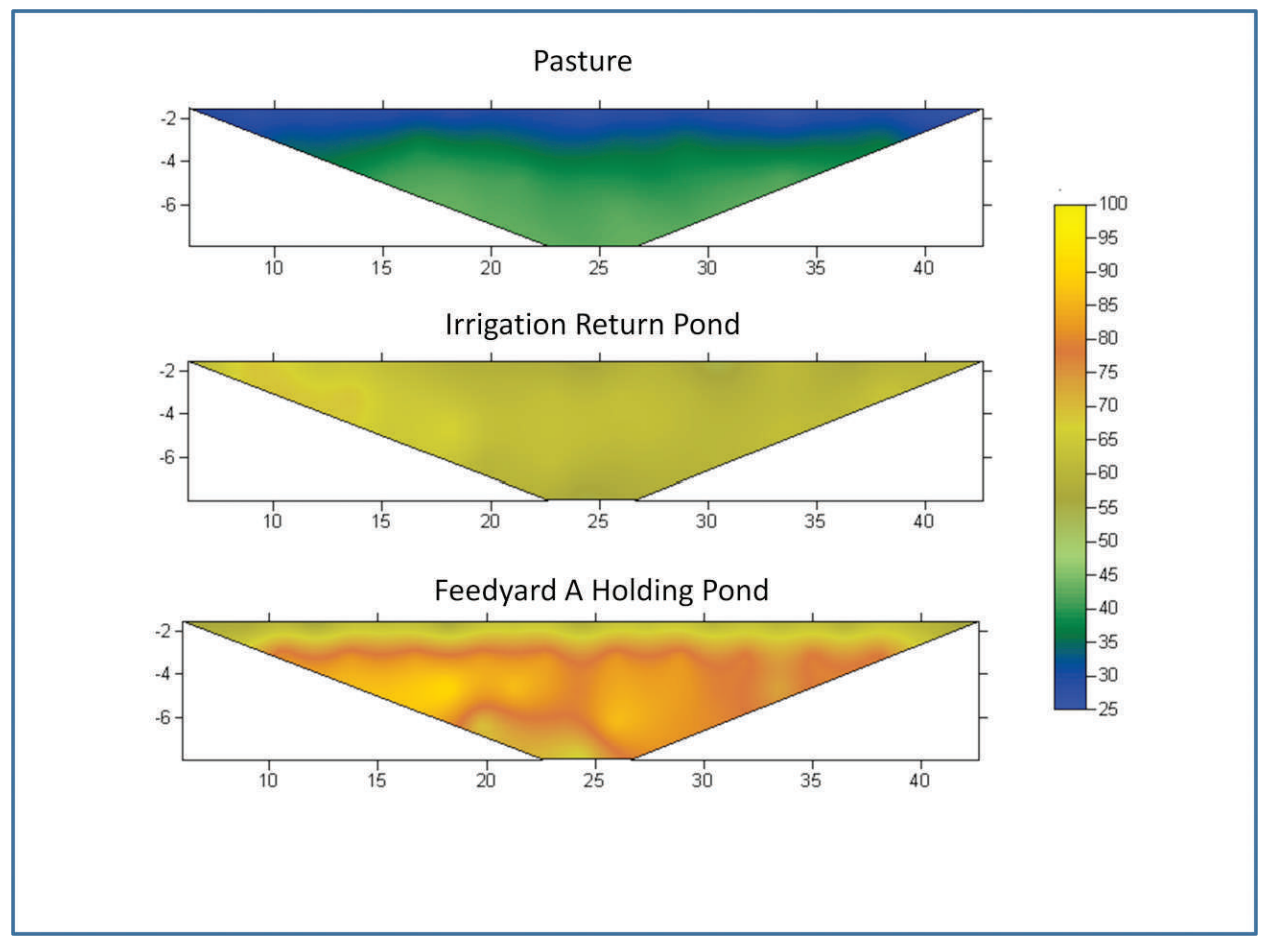

Figure 6. The resulting images (using the same conductivity scale) of the pseudosection demonstrate conductivity differences typified by each site. These images reflect conductivity differences in soils differentially affected by saltladen water.

An estimated depth and resistivity were calculated for each probe configuration using Eqs. 1-3. The resultant data were converted to conductivities to be consistent with previous work involving subsurface electromagnetic soundings. The collection of data points resulted in an inverted triangle that spans approximately $37 \mathrm{~m}$ and extends approximately 12-m deep. The conductivity data is presented as a pseudosection in which the dataset has been interpolated using a Kriging algorithm and then displayed (using Surfer $^{\circledR}$ ) as a vertical slice subsection. The pseudosection only gives a very approximate picture of the true subsurface resistivity/conductivity because the shape of the contours depend on the type of array used as well as the true subsurface conductivity (Loke, 2004). Despite the limitations of the pseudosection plot, this method provides a stable representation of the subsurface slice and a basis for comparison of temporal and spatial changes. Also, the method allows for evaluation of temporal and spatial changes in solution conductivities by digitally differencing selected time-series plots. However, if site information is needed beyond that necessary for monitoring purposes, then a 2-D inversion could be performed on the existing data yielding additional details.

Establishment of methods for applying resistivity arrays to relatively shallow agricultural applications required a series of initial tests. Three sites were chosen at Feedyard A to test the concepts and to delineate soil resistivity profiles; these sites were in the same soil taxonomical series as the holding pond to be evaluated. The three sites are: 1) the edge of the holding pond (Fig. 1) at Feedyard A; 2) "grass land" soil (within $300 \mathrm{~m}$ of Feedyard A) where no fertilizer or animal grazing had occurred within the past 20 years; and 3) the edge of an irrigation reuse pit (within $300 \mathrm{~m}$ downgradient of Feedyard A) that holds field runoff with much lower salt loading than holding pond 2 (Fig. 1). The portable array was set up at each of the three sites and readings were taken with a probe spacing, a, of $3.05 \mathrm{~m}(10 \mathrm{ft})$. The resulting images (using the same conductivity scale) of the pseudosection (Fig. 6) demonstrate conductivity differences typified by each site. The dark colors of the image reflect low conductivity with lighter colors indicating higher conductivity. The image as generated at the grass land site shows a relative low conductivity near the surface with slightly increasing overall conductivity with depth. The irrigation pond demonstrates a conductivity that is higher than the pasture, but quite uniform; this region has been impacted by irrigation water and the water in the holding pond. The conductivity pseudosection slice near the holding pond reveals an elevated conductivity consistent with soil hydrated with 
Eigenberg and Woodbury: Monitoring Groundwater Impacts near Runoff Ponds using Resistivity

salt-laden water. While these images are qualitative, they do indicate the sensitivity of the system by illustrating the impact of animal-derived salts affecting the subsurface conductivity.

The results of the initial tests provided the basis for installation of a permanent, $6.1-\mathrm{m}(20-\mathrm{ft})$ probe spacing, 16-probe array paralleling the south side of holding pond 2 at Feedyard A on May 12, 2011 (Fig. 1). The installation had an effective overall length of approximately $73 \mathrm{~m}$. A trench was used to allow for wire and probe burial. This protected the wires and allowed for typical maintenance of the holding pond (i.e., mowing vegetation). The depth of the trench was approximate $0.3 \mathrm{~m}$. A junction box was installed on metal t-posts to allow access to the terminal end of the probe connections for data collection.

The same procedure was use to install an array at Feedyard B on June 28, 2011. A series of tests (data not shown) at varying distances adjacent to the pond helped identify an ideal site for the array. The chosen site was located between two rows of monitoring wells (Fig. 2). The Feedyard B array used a closer spacing, $3.05 \mathrm{~m}$, than Feedyard A, but included a higher density array (32 probes, with 155 distinct Wenner-Alpha combinations). This installation spanned approximately $85 \mathrm{~m}$ in length. A trencher was also used to bury the probes and wires to an approximate depth of $0.5 \mathrm{~m}$. These probes and wires were buried deeper than at Feedyard A because part of the array at Feedyard B extended into an agricultural field. This deeper depth was necessary to place the probes and wires below any tillage operation.

Weekly data collection was performed at both Feedyard A and B. Each collection date was analyzed visually for changes from the previous surveys. Additional analysis included differenced maps that were generated digitally by subtracting the previous week's data from the current week being evaluated. This provided a visual inspection of the change in solution conductivity. Difference maps proved to be powerful tools with two distinct advantages: 1) a difference map eliminated stable features that were common to both maps (i.e., soil properties and geologic features) so fixed features were minimized, and 2) a difference map accentuated the differences that occurred over relatively short intervals.

A pseudosection image generated from Feedyard A on August 25, 2011, with a subsequent difference map of August 25 minus August 18 revealed a significant anomaly. Investigation led to excavating the previously buried wires, which identified rodent damage on one of the connecting wires. The array was re-installed on October 4, 2011, with conduit supplying protection for the buried wires and probes penetrating the conduit at junction boxes.

\section{Results and Discussion}

$\underline{\text { Feedyard A }}$

Data were collected weekly from Feedyard A beginning May 2, 2011, through February 15, 2012, with the exception of August 25 through October 4, 2011, because of rodent damage to the wiring. Visual inspection indicates little change throughout the season. Figure 7(a)-(b) presents pseudosection images from two survey dates; each figure reveals a pattern of high estimated conductivities near the soil surface showing decreasing conductivity with depth. The pond site is within $300 \mathrm{~m}$ of the pasture survey, which demonstrated uniform low conductivities (Fig. 6); however, the nearby pond survey reveals a conductivity pattern that appears to be impacted by the pond. The observed pattern suggests a "zone of hydration" (Fig. 8) that surrounds typical holding ponds. In low conductivity soils, the "zone of hydration" has limited extent. The impact of this "zone of hydration" becomes a concern if solutes from the pond intercept underlying ground water or are readily transported to receiving water.

The stability of the images and the associated conductivities was tested using difference maps with a typical difference map of the Feedyard A site shown in Fig. 7(c). The difference map in Fig. 7(c) shows very little change in conductivity during the week being analyzed. This season-long stability was indicative of a stable runoff control system. The two images of Fig. 7(a-b) appear relatively stable; however, the October image, when compared with the February image, reveals a slightly higher upper-level conductivity. The effect of temperature upon soil conductivity is well documented (McNeill, 1980), with an increasing temperature increasing soil electrical conductivity. Previous work (Eigenberg et al., 2006) has documented that subsurface temperatures are cyclic with seasonal peak highs and lows being delayed when compared to surface temperatures. The extent of this delay is directly related with the depth of the measure. For this region, at three meters depth the highest temperature occurs in October (about $15.3^{\circ} \mathrm{C}$ ) and the lowest occurs in April (about $8.9^{\circ} \mathrm{C}$ ), with an approximate range of $7.4^{\circ} \mathrm{C}$. An increase of $7.4^{\circ} \mathrm{C}$ would predict an approximate $10 \mathrm{mS} \mathrm{m} \mathrm{m}^{-1}$ increase in soil conductivity. This is consistent with displayed differences of the two images shown in Fig. 7.

\section{Feedyard B}

Feedyard B has been continuously monitored on a weekly basis beginning June 28, 2011, with data collected through February 15, 2012. Figure 9(a) is a pseudosection image that was measured on July 27, 2011. The array at Feedyard B (as detailed in Materials and Methods) is a higher density array (32 probes on 
Journal of Environmental and Engineering Geophysics

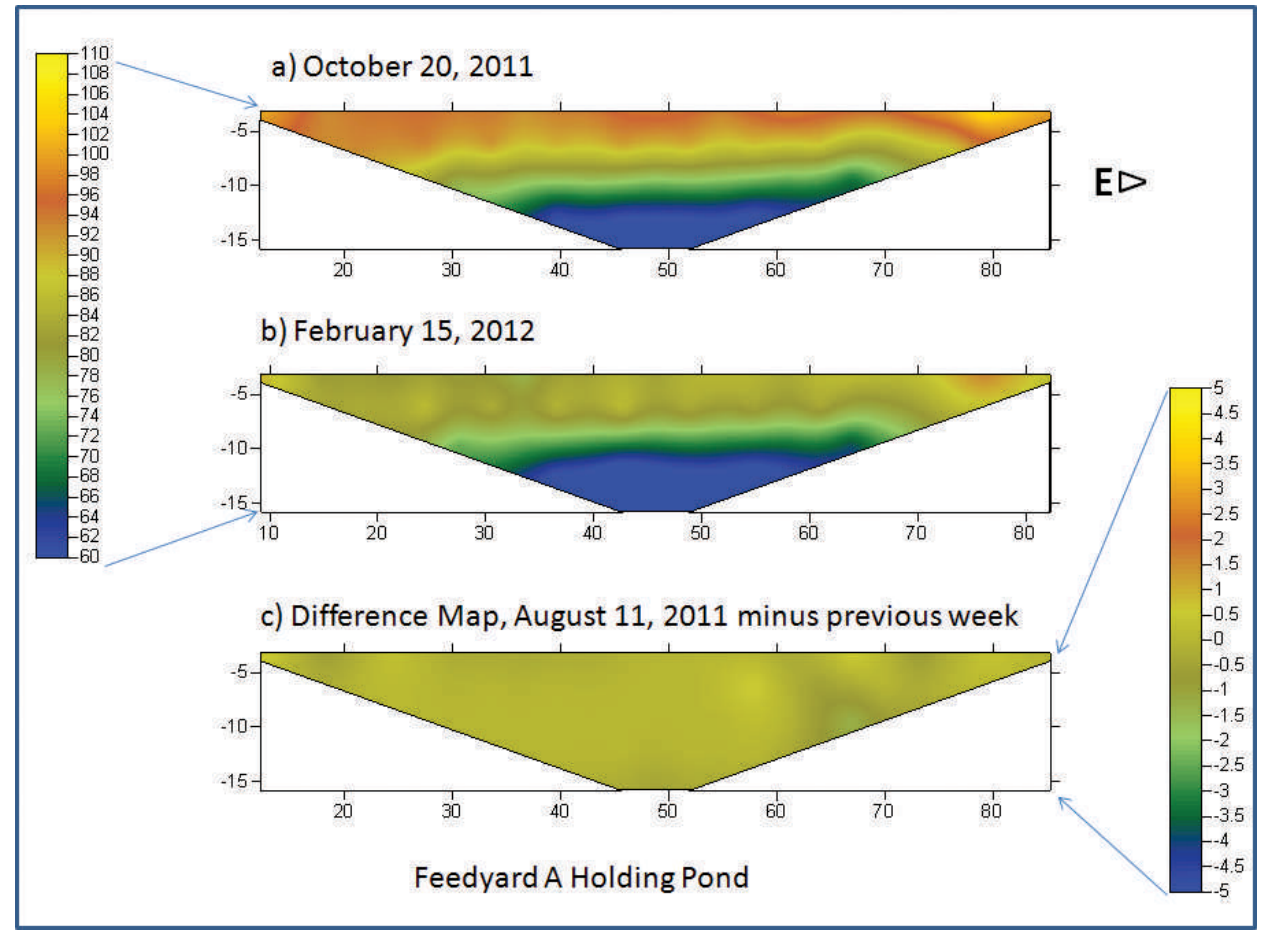

Figure 7. Pseudosection images from two survey dates (a and b) of Feedyard A; each figure reveals a pattern of high estimated conductivities near the soil surface showing decreasing conductivity with depth. The difference map in (c) shows very little change in conductivity during the week being analyzed. This season-long stability was indicative of a stable runoff control system. Note that the image of the holding pond in Fig. 6 was generated using a different probe spacing and display scaling; these factors account for the different appearance between the two figures.

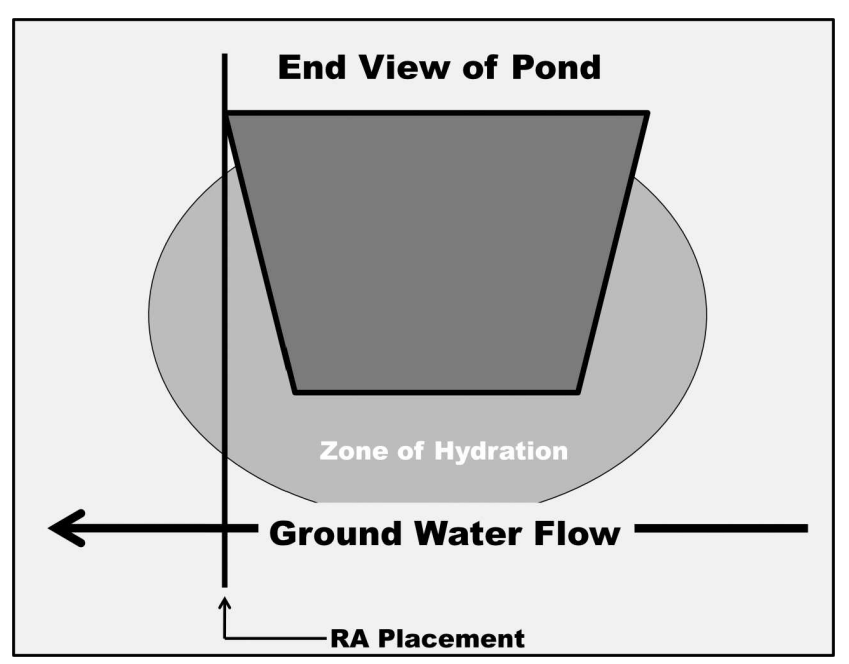

Figure 8. The observed pattern in Fig. 6 suggests a "zone of hydration" that surrounds typical holding ponds. In low conductivity soils the "zone of hydration" has limited extent. The impact of this "zone of hydration" becomes a concern if solutes from the pond intercept underlying ground water or are readily transported to receiving water. 3.05-m spacing spanning $85 \mathrm{~m}$ ). This installation (Fig. 2) provided a profile that spanned across the southeast end of the holding pond and extending past the northeast end into the crop field north of the pond. The soils at this site are nearly level and were formed in recent alluvium on flood plains of larger streams. As such, the permeability is moderate or moderately slow in the solum, but the substratum is very rapid. The depth to ground water is approximately $4 \mathrm{~m}$, but varies greatly throughout the season. Figure 9(a) shows an apparent effect of the holding pond at the left of the image near the surface. However, this "zone of hydration" appears to extend deeper (compared with Figs. 7(a)-(b) of Feedyard A) into the substratum, and appears to affect conductivity levels across the entire left side of Fig. 9(a). Earlier surveys taken 16- and 32-m further away from the edge of the pond to the east (data not shown) had displayed low conductivities; however, as the survey neared the perimeter of the pond elevated conductivities were observed - consistent with high conductivity solution seeping from the holding pond. Furthermore, the north (rightmost) region of Fig. 9(a) reflects low conductivities as the image moves further from the pond's influence. 
Eigenberg and Woodbury: Monitoring Groundwater Impacts near Runoff Ponds using Resistivity

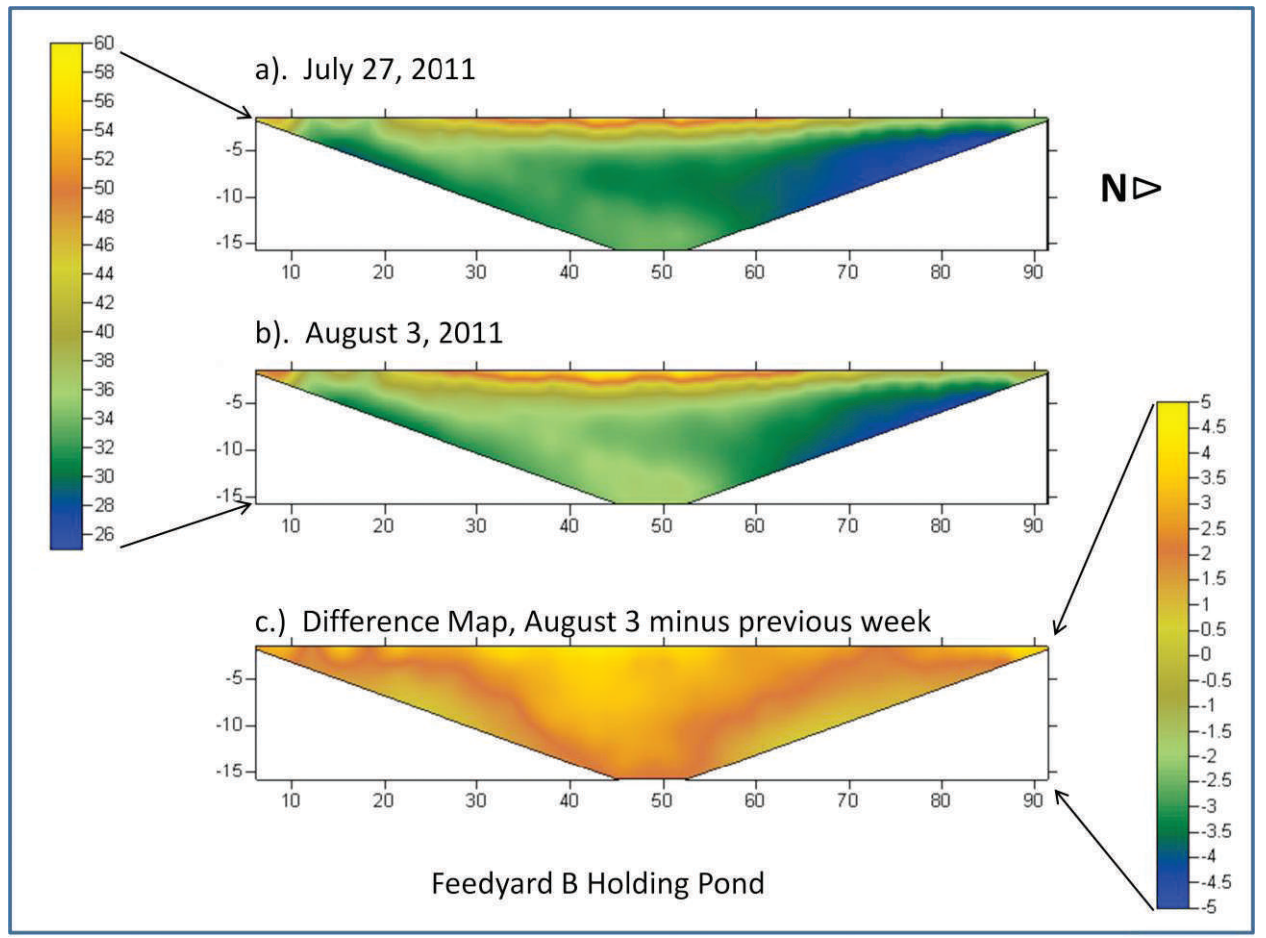

Figure 9. a) Apparent effect of the holding pond at the left of the image near the surface. However, this "zone of hydration" appears to extend deeper (compared with Figs. 7(a and b) of Feedyard A) into the substratum, and appears to affect conductivity levels across the entire left side of the figure. A difference map (c) was created that subtracted the July $27^{\text {th }}$ pseudosection image from the August $3^{\text {rd }}$ pseudosection image (b), and provides a dramatic visualization of a dynamic subsurface event resulting from a management operation.

Unlike Feedyard A, the holding pond site at Feedyard B demonstrated changes in subsurface conductivities over a relatively short time span. Two images are shown in Figs. 9(a)-(b); one was created on July 27, 2011, the second was one week later on August 3, 2011. Late July and early August are periods that typically involve irrigation of cropland in this region; the holding pond water is a good source of nutrient laden irrigation water useful for crop production. Irrigation from this pond was begun after the July $27^{\text {th }}$ date and continued through the monitoring date of August $3^{\text {rd }}$. Removing water from the pond for irrigation can inadvertently disrupt the organic seal at the bottom of the holding pond and provide a pathway for pond water to be discharged into the surrounding soils. The coarse textured substratum allowed for the seepage to rapidly permeate to the surrounding down-gradient area. Figure 9(b) shows the pond during a pumping event; a comparison of Figs. 9( $a$ and b) reveals a noticeable increase in conductivity in the vicinity of the pond on August 3. A difference map was created, which subtracted the July $27^{\text {th }}$ pseudosection image from the August $3^{\text {rd }}$ pseudosection image. Figure 9(c) displays the resulting difference map and provides a dramatic visualization of a dynamic subsurface event resulting from a management operation. This effect was diminished, but still apparent in the subsequent data set (data not shown) one week later. This sequence demonstrates the sensitivity of this geophysical tool to monitor and detect changes that result from altered subsurface conductivities.

This study has established the need to calibrate the conductivity dynamics measured by the resistivity array with actual measures of the soil and groundwater system. The physical and chemical properties of soil sampling versus aquifer sampling at each site are distinctly different and require specific sampling protocols. Continuous measurement of levels of liquid within the pond will provide additional insight into the pond environment interface. Additionally, soil and aquifer profile temperatures are needed to adjust for seasonal variations for comparative purposes.

\section{Conclusions}

This work was undertaken to test a method of monitoring cattle feedyard holding ponds. The initial work was exploratory; but, it has led to a collection of data, that, when taken together supports the use of resistivity arrays as a sensitive, robust, stable monitoring method. The data analysis method of interpolating the 
Journal of Environmental and Engineering Geophysics

raw resistivity array data allowed for digitally differencing select time-series plots. This provided a means to evaluate changes in solution conductivity within the plot profile as affected by the holding pond. This technique can be used to establish a benchmark for determining whether any changes detected met a pre-determined threshold that a leak event has occurred. The resistivity array system and data analysis protocol, in conjunction with appropriate computer-based hardware and software, could conceivably have value for unattended monitoring of agricultural liquid waste management sites. Additional work is required to validate these initial findings. A series of experiments are planned that will include continued frequent resistivity array data collections, periodic water samples from monitoring wells, deep soil cores to validate resistivity profiles and soil temperature profile data. Also, future work will include the use of inversion methods to convert resistivity array data to evaluate site profile characteristics. This information will be particularly useful for determining the best location to permanently locate an array for monitoring a holding pond and for predicting the longterm impact of holding ponds on the surrounding soil and groundwater systems.

\section{Acknowledgments}

The authors would like to acknowledge the participation of the producer cooperator located in central Nebraska designated as Feedyard B; these cooperators have unselfishly offered their resources for research to find better ways to monitor and maintain similar facilities. These good stewards of the land are working with the Nebraska Department of Environmental Quality, university researchers and USDA researchers in the collaborative efforts.

Additionally, this work was enhanced greatly by the fabrication skills of John Holman, research technician. His diligence and creative insights helped move this project forward.

The research was conducted in cooperation with the Nebraska Department of Environmental Quality, The Nebraska Cattlemen Association and with the support of University of Nebraska and AgraTek Corp.

\section{References}

Allred, B.J., Groom, D., and Reza Ehsani, M., 2008, Resistivity methods: in Handbook of agricultural geophysics, Allred, B.J. (ed.), CRC Press, Boca Raton, FL.

Barcelona, M.J., Gibb, J.P., and Miller, R.A., 1983, A guide to the selection of materials for monitoring well construction and ground-water sampling: Illinois State Water Survey Department of Energy and Natural Resources Champaign, Illinois, SWS Contract Report 327.

Bacelona, M.J., Helfrich, J.A., and Garske, E.E., 1985, Sampling tubing effects on groundwater samples: Analytical Chemistry, 57(2) 460-464.
Barrington, S.F., and Madramootoo, C.A., 1989, Investigating seal formation from manure infiltration into soils: Transactions of ASAE, 32(3) 851-856.

Carpenter, P.J., Kaufmann, R.S., and Price, B., 1990, Use of resistivity soundings to determine landfill structure: Ground Water, 28(4) 569-575.

Chang, A.C., Olmstead, W.R., Johansos, J.B., and Yamashita, G., 1974, Sealing mechanism of wastewater ponds: Journal of Water Pollution Control Federation, 46(7) 1715-1721.

Cihan, A., Tyner, J.S., and Wright, W.C., 2006, Seal formation beneath animal waste holding ponds: Transactions of the ASABE, 49(5) 1539-1544.

Culley, J.L.B., and Phillips, P.A., 1982, Sealing of soils by liquid cattle manure: Canadian Agricultural Engineering, 24(2) 87-89.

De Tar, W.R., 1979, Infiltraton of liquid dairy manure: Transactions of ASAE, 22(3) 521-528.

Dolliver, H.A.S., and Gupta, S.C., 2008, Antibiotic losses from unprotected manure stockpiles: Journal of Environmental Quality, 37, 1238-1244.

Eigenberg, R.A., Nienaber, J.A., Woodbury, B.L., and Ferguson, R.B., 2006, Soil conductivity as a measure of soil and crop status-a four year study: Soil Science Society of America Journal, 70, 1600-1611.

Gilley, J.E., Vogel, J.R., Berry, E.D., Eigenberg, R.A., Marx, D.B., and Woodbury, B.L., 2009, Nutrient and bacterial transport in runoff from soil and pond ash amended feedlot surfaces: Transactions of the ASABE, 52(6) 2077-2085.

Ham, J.M., 1999, Measuring evaporation and seepage losses from lagoons used to contain animal waste: Transactions of ASAE, 42(5) 1303-1312.

Loke, M.H., 2004. Tutorial: 2-D and 3-D electrical imaging surveys, Geotomo Software, www.geoelectrical.com, Gelugor, Penang, Malaysia.

McNeill, J.D., 1980. Electrical conductivity of soils and rocks, Technical Note TN-5, Geonics Ltd., Mississauga, Ontario, Canada.

Miller, M.H., Robinson, J.B., and Gillham, R.W., 1985, Selfsealing of earthen liquid manure storage ponds: 1 . A case study: Journal of Environmental Quality, 14(4) 533-538.

NDEQ, 2011, 2010 Nebraska water monitoring report: Nebraska Department of Environmental Quality, Water Quality Division.

Parker, D.B., Auvermann, B.W., and Williams, D.L., 1999a, Comparison of evaporation rates from feedyard pond effluent and clear water as applied to seepage predictions: Transactions of ASAE, 42(4) 981-986.

Parker, D.B., Eisenhauer, D.E., Schulte, D.D., and Martin, D.L., 1999b, Modeling seepage from an unlined beef cattle feedlot runoff storage pond: Transactions of ASAE, 42(5) 1437-1445.

Roswell, J.G., Miller, M.H., and Groenevely, P.H., 1985, Selfsealing of earthen liquid manure storage ponds: II. Rate and mechanism of sealing: Journal of Environmental Quality, 14(4) 539-543.

Tyner, J.S., and Lee, J., 2004, Influence of seal and liner hydraulic properties on the seepage rate from animal waste holding ponds and lagoons: Transactions of ASAE, 47(5) 1739-1745. 